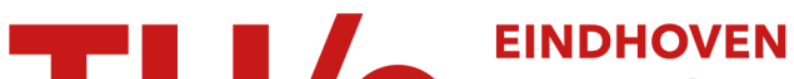 UNIVERSITY OF TECHNOLOGY
}

\section{Data center connectivity by $6 \mathrm{G}$ wireless systems}

Citation for published version (APA):

Rommel, S., Raddo, T. R., \& Tafur Monroy, I. (2018). Data center connectivity by 6 G wireless systems. In K. Manousakis, S. lezekiel, I. Tomkos, K. Utaka, \& G. Ellinas (Eds.), Proceedings of the 2018 Photonics in Switching and Computing, PSC 2018 [8751363] Institute of Electrical and Electronics Engineers. https://doi.org/10.1109/PS.2018.8751363

DOI:

10.1109/PS.2018.8751363

Document status and date:

Published: 01/09/2018

\section{Document Version:}

Accepted manuscript including changes made at the peer-review stage

\section{Please check the document version of this publication:}

-A submitted manuscript is the version of the article upon submission and before peer-review. There can be important differences between the submitted version and the official published version of record. People interested in the research are advised to contact the author for the final version of the publication, or visit the $\mathrm{DOI}$ to the publisher's website.

- The final author version and the galley proof are versions of the publication after peer review.

- The final published version features the final layout of the paper including the volume, issue and page numbers.

Link to publication

\section{General rights}

Copyright and moral rights for the publications made accessible in the public portal are retained by the authors and/or other copyright owners and it is a condition of accessing publications that users recognise and abide by the legal requirements associated with these rights.

- Users may download and print one copy of any publication from the public portal for the purpose of private study or research.

- You may not further distribute the material or use it for any profit-making activity or commercial gain

- You may freely distribute the URL identifying the publication in the public portal.

If the publication is distributed under the terms of Article 25fa of the Dutch Copyright Act, indicated by the "Taverne" license above, please follow below link for the End User Agreement:

www.tue.nl/taverne

Take down policy

If you believe that this document breaches copyright please contact us at:

openaccess@tue.nl

providing details and we will investigate your claim. 


\title{
Data Center Connectivity by 6G Wireless Systems
}

\author{
Simon Rommel, Thiago R. Raddo, and Idelfonso Tafur Monroy \\ Institute for Photonic Integration \\ Eindhoven University of Technology \\ Eindhoven, The Netherlands \\ \{s.rommel, t.r.raddo, i.tafur.monroy\}@tue.nl
}

\begin{abstract}
Wireless connectivity and photonic-wireless links in data centers allow fast deployment and dynamic reconfigurability. Technological advances in millimeter and sub- $\mathrm{THz}$ communications will soon go beyond $5 G$ and trigger $6 \mathrm{G}$ systems. We present how data centers could benefit from such $6 \mathrm{G}$ technologies, particularly in assuring flexibility and adaptability, without compromising scalability.

Index Terms-Wireless data centers, 6G, millimeter wave communications, optical wireless communications, data center networks.
\end{abstract}

\section{INTRODUCTION}

The recently started cloud computing era and its huge demand for data processing and storage has been one of the major driving factors for the emergence of highly flexible and reconfigurable and high density data centers. The use of state-of-the-art technologies to simplify data centers regular operations so that they can scale along with benefits like economies of fast deployment and better manageability, are common solutions to the growing demand of cloud computing services. Though data centers in the past had been used mainly for data storage purposes, they have recently become powerful facilities capable of processing, and analyzing vast amounts of data nearly instantly, requiring ultra-low latency, high capacity as well as transmission rates.

The demand for increased communications bandwidth in data centers has several costs associated with it and providing sufficient connectivity in a manner that is both scalable and cost-effective has become a challenging task in data center design. The expenses related to cabling in data centers typically represent roughly $8 \%$ of the total infrastructure costs [1] and installation and network configuration for wired connections are complex, cumbersome and often inefficient. Moreover, wired typologies render the network static and inflexible, not only impacting energy efficiency, but also scalability of the overall data center. Typical data center network architectures are based on scale-up hierarchical designs such as fat-tree and butterfly, which have drawbacks like poor reconfigurability and scalability [2].

Modern data centers, designed to cope with the large and dynamic demand of virtualized services and cloud computing, rely on modular layouts to allow reallocation of resources on demand. In such data centers both flexibility and adaptability

This work was partially funded by the blueSPACE and 5G PHOS projects, which received funding from the European Union's Horizon 2020 programme under grant agreement numbers 762055 and 761989. are essential and a communications infrastructure is required that is scalable on one hand and highly reconfigurable on the other. In this context, wireless data center networking has been introduced to improve data center connectivity and circumvent current bottlenecks or even to enable fully wireless data centers [3], [4]. The technologies for millimeter-wave (mm-wave) transmission developed for the fifth generation of mobile networks (5G), i.e., converged optical and wireless networking with radio frequency (RF) carriers of tens of $\mathrm{GHz}$ and beamforming with multi-element antenna arrays, provide a technology candidate to deploy high capacity and high density data centers. With dynamic beamforming and full wireless connectivity, these data centers profit from the flexibility of wireless communications and by offering physical reconfigurability, allow the layout of the network to be changed dynamically in a cost-efficient and straightforward way.

While $5 \mathrm{G}$ is yet to see deployment, the discussion on what 6G may be has gained significant importance with $6 \mathrm{G}$ being touted as the next big trend after the revolution that is $5 \mathrm{G}-$ or decried as a technology that may never happen [5]-[7]. As more and more features are discussed as defining factors of 6G, this paper will focus on their applicability in data center networks and discuss $6 \mathrm{G}$ as a potential option for future data center networks and data centers as an application for $6 \mathrm{G}$. We perceive $6 \mathrm{G}$ systems in data center networks to cope with demanding requirements such as power consumption, cooling efficiency, physical space, and network reconfigurability, where fiber-only solutions cannot fully satisfy such conditions.

\section{6G TeChNOLOGIES For WiREless Data CENTER COMMUNICATIONS}

The range of technologies discussed for introduction with 6G ranges from continuation of technology advances made in $5 \mathrm{G}$, e.g., with respect to using ever higher carrier frequencies supporting ever larger bandwidths and shaping RF beams to concentrate energy in a smaller spatial region, to the introduction of novel applications, concepts and technologies such as self-configuring networks based on artificial intelligence, satellite roaming and direct human to human communication via implants.

\section{A. Spectrum Unification for Wireless Data Center Intercon- nects}

Spectrum unification and the concurrent use of spectrum from entirely different frequency bands such as the traditional 


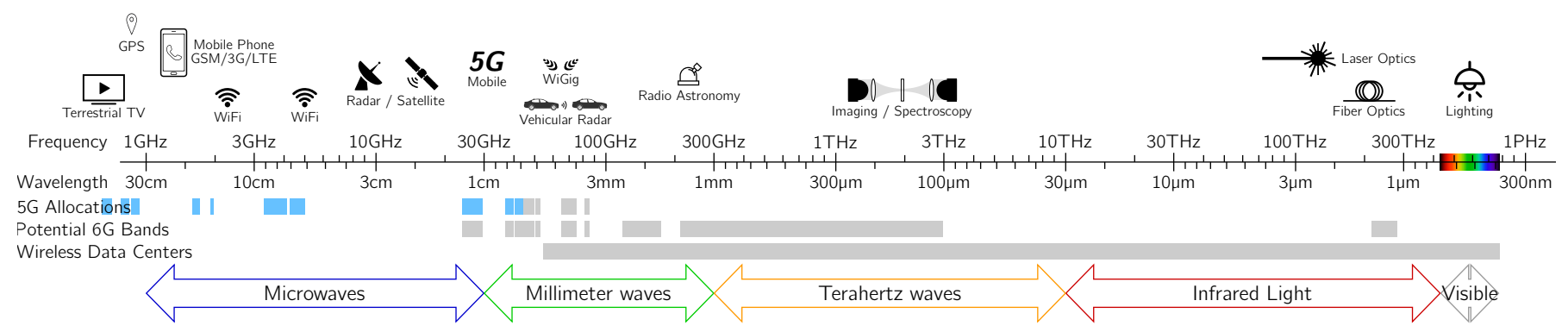

Fig. 1. Electromagnetic spectrum from microwave to visible light, showing typical applications in the different spectrum ranges (top) and allocations for 5G, $6 \mathrm{G}$ and spectrum unification for wireless data center networks (bottom).

mobile bands, the mm-wave and $\mathrm{THz}$ regions, and even optical frequencies is considered a major building block for $6 \mathrm{G}$ networks. Figure 1 illustrates the applicable spectrum from microwaves to visible light along with typical applications, allocations for $5 \mathrm{G}$ as well as the spectrum available for spectrum unification for wireless data center networks.

The development of the used RF spectrum that has seen $5 \mathrm{G}$ networks not only extend the available spectrum in the region below $6 \mathrm{GHz}$, but also moving into entirely new spectrum in the mm-wave region is set to continue beyond 5G. While the latter target frequencies just below $30 \mathrm{GHz}$ for early deployments and frequencies at $40 \mathrm{GHz}$ are included in the latest standards [8], for $6 \mathrm{G}$ the use of the entire $\mathrm{mm}$-wave spectrum up to $100 \mathrm{GHz}$ and beyond can be predicted. In addition to the mm-wave spectrum however, $6 \mathrm{G}$ will likely look beyond towards the $\mathrm{THz}$ range, which is rapidly being explored by wireless communications research [9], [10]. While facing many similar issues, $\mathrm{THz}$ transmission provides significantly larger bandwidths in a largely unregulated frequency space.

Finally, even further towards higher frequencies, optical wireless communications, i.e., the transmission of collimated optical beams through open space, rather than through optical fibres, has been shown to offer large capacities and was suggested as alternative for data center networking [2], [4]. Compared to $\mathrm{mm}$-wave or and $\mathrm{THz}$ wave wireless links, free space optics (FSO) in the near infrared - including the typical fiber optics wavelengths at $850 \mathrm{~nm}, 1310 \mathrm{~nm}$ and $1550 \mathrm{~nm}$ - or visible light regions not only offer even larger spectrum availability, but potentially also improved transmission characteristics, higher transmitter density, avoidance of RF interference and improved spectrum reuse - resulting in large potential for very high connection density at a high capacity per connection.

As the development for mechanisms and algorithms to enable spectrum unification will be a cornerstone of the development for $6 \mathrm{G}$, its application to wireless data center networks appears as logical step, constituting an important use case in addition to the many use cases defined for $5 \mathrm{G}$ and envisioned for $6 \mathrm{G}$.

\section{B. Beamforming and Spatial Distribution}

In order to efficiently work at $\mathrm{mm}$-wave or $\mathrm{THz}$ frequencies, the transmitted energy must be focused onto a small area to overcome the high path loss and ensure sufficient signal to noise ratio (SNR). While in legacy point to point mm-wave link this is achieved with high gain reflector antennas, for $5 \mathrm{G}$ and beyond the focus is on phased antenna arrays, allowing not only a similarly confined beam, but also directional steering and spatial multiplicity by multi-beam transmission. For the use in data center networks, the latter is a key characteristic, as it allows the transmission of many beams - as many as there are antenna elements - from the same array, while at the same time all beams can be independently steered [1], [4]. Beam steering for FSO can be achieved in a similar fashion, but a range of other technologies are under development to allow more simple implementations of two-dimensional steering, including micro mechanical mirrors and fully integrated photonic chips based on tuneable lasers [2], [4].

The transmission of many beams from a single emitter array and the dynamic steering of beams are of key interest to wireless data center networks. Emitter arrays allow a high density of connections where the number of beams and - at least theoretically - SNR positively scale with the array dimensions, while beam steering allow the network to be dynamically reconfigured to meet changing loads and requirements.

\section{Adaptive and Self-Configuring Networks}

Artificial intelligence (AI) is suggested to play a key role in 6G networks [7], [11] and its application for optimization of data center networks has been suggested [12]. While optimization of network behaviour in so-called cognitive radio networks is widely studied, the use of AI in data centers has often focused on improving energy efficiency rather than on network configuration optimization. With the introduction of wireless connectivity in data centers, the possibility to physically reconfigure the network during runtime opens a new alley for AI to explore and to exploit by dynamically changing the network structure to best fit the current or predicted load.

Initially, the use of AI might follow existing paths in analyzing traffic patterns and load distribution, as well as the characterization of link conditions between different end points [13]. However, as is suggested for $6 \mathrm{G}$ networks, the true power of AI will only come to play if it is employed not only to analyze an existing network layout, but also to optimize it with the possibility of changing the physical configuration.In data centers, where with wireless connectivity a more densely 


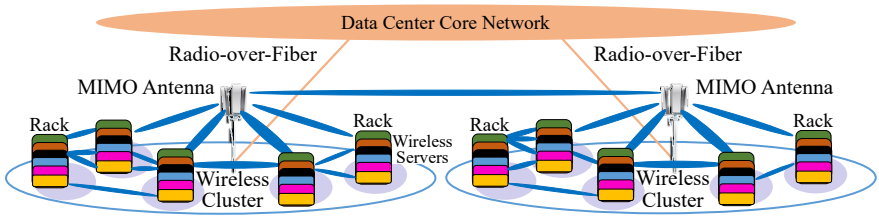

Fig. 2. Wireless data center network layout, based on clusters of racks of wireless servers, wirelessly connected between servers, between racks and between clusters.

mashed network can be established, dynamic reconfiguration by AI may be the only feasible option to ensure the network will scale without impact on performance and efficiency.

\section{Wireless Data Center Network Layouts}

Most research work found in the current literature deals with wired data center networks and traditional topologies like fattree and butterfly. Today's data center connections are below $100 \mathrm{~m}$ and several well-known layouts can be used to design as well as build a network [4]. Server farms are often built with physical separation between racks consisting of thousands of devices like data storage, servers and switches. For example, both servers and switches of a data center can be arranged into racks in the way that they form a hexagonal structure so that direct line-of-sight wireless channels are easily created and operated [4]. In such an example, where traditional topology architectures are considered, each rack has two transceivers with a transceiver using beamforming along with phased array to achieve highly directional links, whereas a phase shifter can be used to steer the beam allowing communication with different servers. A survey about several data center network topologies is found in [4].

Regardless of the network layout, a great deal of effort is required for an alternative solution that supports future interconnect speeds and increasing data center sizes. Indeed, a new data center network topology should be considered, moving network intelligence into the hosts and considering innovative wireless technology. In this way, we perceive the introduction of a wireless data center network layout illustrated in Fig. 2 for real-world deployments as next trends to achieve high capacity at low cost. The architecture layout consists of racks that are arranged in a mesh topology resulting in a densely connected sub-graph. Multiple-input and multipleoutput (MIMO) antenna transceivers are deployed in each server node, where the antennas are used for both intra- and inter-rack wireless communication. A wireless switch connects the transceivers of a server to its system bus and a routing protocol is used to send packets within the switch. This solution provides non-stop services as new on-demand services can be included without interrupting the data center operation, having greater fault-tolerance and spectrum efficiency. Moreover, such a wireless network can be easily expanded and consequently scale up to different needs and data traffic volumes.

This innovative wireless network can be deployed using mm-wave or THz RF technology or FSO and, taking advantage of the spectrum unification, a combination thereof. In this fashion, a fully wireless system with flexible, reconfigurable, and scalable features can potentially be build based on the recent developments and advances in high-capacity wireless communications and the technologies suggested for 6G [14].

\section{Conclusions}

In this paper, we have discussed the introduction of innovative concepts envisioned for $6 \mathrm{G}$ wireless communications to data center networks. The predicted unification of spectrum from millimeter wave over $\mathrm{THz}$ to visible light allows wireless data center networks to achieve sufficient capacity and when combined with dynamic beam steering might pave the way towards a single, interoperable, and dynamic solution for flexible deployment of modular data centers in a cost-efficient manner. The suggested use of AI for network optimization and configuration and the introduction of new network architectures serve to fully utilize the additional flexibility and physical reconfigurability of wireless data center networks. The adoption of technologies suggested for $6 \mathrm{G}$ wireless and of data center networks as an additional use case of $6 \mathrm{G}$ may benefit both sides through the development of flexible and yet interoperable technologies and a unified spectrum for wireless and free space optical communications.

\section{REFERENCES}

[1] H. Vardhan, S.-R. Ryu, B. Banerjee, and R. Prakash, "60 GHz wireless links in data center networks," Computer Networks, vol. 58, pp. 192 205, Jan. 2014.

[2] C. Chaintoutis et al., "Free space intra-datacenter interconnects based on 2D optical beam steering enabled by photonic integrated circuits," Photonics, vol. 5, no. 3, p. 21, Aug. 2018.

[3] Y. Cui, H. Wang, X. Cheng, and B. Chen, "Wireless data center networking," IEEE Wireless Commun., vol. 18, no. 6, pp. 46-53, Dec. 2011.

[4] A. S. Hamza, J. S. Deogun, and D. R. Alexander, "Wireless communication in data centers: A survey," IEEE Commun. Surveys Tuts., vol. 18, no. 3, pp. 1572-1595, 2016.

[5] CarphoneWarehouse. (2017) 5G: what it means and why there will never be a 6G. [Online]. Available: https://business.carphonewarehouse. com/expert/5g-means-will-never-6g/

[6] K. David and H. Berndt, " $6 \mathrm{G}$ vision and requirements: Is there any need for beyond 5G?" IEEE Veh. Technol. Mag., vol. 13, no. 3, pp. 72-80, Sep. 2018

[7] A. Gatherer, "What will 6G be?" IEEE ComSoc Technol. News, Jun. 2018.

[8] 3GPP TS 38.104, "NR: Base station (BS) radio transmission and reception," 3GPP, Valbonne, Technical Report, Rel. 15, Mar. 2018.

[9] J. Federici and L. Moeller, "Review of terahertz and subterahertz wireless communications," J. Appl. Phys., vol. 107, no. 11, p. 111101 , Jun. 2010.

[10] I. F. Akyildiz, J. M. Jornet, and C. Han, "Terahertz band: Next frontier for wireless communications," Physical Communication, vol. 12, pp. 16-32, Sep. 2014.

[11] M. G. Kibria, K. Nguyen, G. P. Villardi, O. Zhao, K. Ishizu, and F. Kojima, "Big data analytics, machine learning, and artificial intelligence in next-generation wireless networks," IEEE Access, vol. 6, pp. 32328 32338,2018

[12] J. Gao. (2014) Machine learning applications for data center optimization. [Online]. Available: https://ai.google/research/pubs/pub42542

[13] J. Mata et al., "Artificial intelligence (AI) methods in optical networks: A comprehensive survey," Opt. Switch. Netw., vol. 28, pp. 43-57, Apr. 2018.

[14] R. Puerta, S. Rommel, J. J. Vegas Olmos, and I. Tafur Monroy, "Optically generated single side-band radio-over-fiber transmission of 60Gbit/s over 50m at W-band," in Proc. Optical Fiber Communication Conference. OSA, 2017, p. M3E.4. 